\title{
DEVELOPMENT OF AUTOMATED CONSTRUCTION WORK EXECUTION TECHNOLOGY USING LASER BEAMS
}

\author{
Ryoji Yoshitake; New Production System Development Department, \\ Building Construction Division \\ Muneyoshi Matsuo, Katsuhiko Kawakami; Machine Development Section, \\ Machinery Department, Civil Engineering Division \\ Fujita Corporation \\ 4-6-15 Sendagaya, Shibuya-ku, \\ Tokyo, 151, Japan
}

\section{SUMMARY}

This paper begins with a description of the dissemination of laser levels and the present status of measuring instruments. This is followed by an introduction of development evolution, equipment outline and the results of performance tests regarding a concrete levelling robot and an automatic level marker presented as the development examples of the proposed automated construction work execution technology using laser beams. It concludes with a description of the utilizability of laser beams to ensure automated/robotized on-site construction work.

\section{INTRODUCTION}

The initial introduction of laser levels into construction sites in Japan dates back to about a decade ago. At first, the passing location of a rotating laser beam being emitted from a beam emitter had to be visually captured. And the use of laser beams in a range harmless to man caused a dispersion of laser beams, which therefore interrupted the dissemination of laser emitters in the construction industry.

With a laser beam receiver soon developed, its dissemination rapidly advanced, mainly aiming at the saving of labor required in measuring work to determine the finishing floor surface of concrete being piaced. Furthermore, an increasing accuracy (the resolving power) of laser beam receivers has created new areas for other types of works requiring level accuracy.

At present, laser beam receivers are extensively used at a considerable number of construction sites, greatly contributing to the saving of labor in level surveying work. Approximately $70 \%$ of Fujita's construction sites are at all times provided with laser levels. In addition, many plasterers and form carpenters generally use laser levels, and this indicates a remarkable dissemination ratio.

This paper exemplifies how the horizontal surveying technology using laser levels, which at present are used only in the field of measurement, was linked to construction machines and evolved into an automated/robotized construction work execution system, and then adds considerations to the feasibility of developing it into one using laser beams for exclusive use at construction sites.

\section{PRESENT Status of LASER LEVELS}

Table 1 gives the major specifications of laser levels and their attached beam receivers available on the market, and Table 2 gives the major specifications of data memory type beam receivers for use in 
Table 1. Major specifications of laser levels and their attached beam receiver which are available on the market

\begin{tabular}{|c|c|c|c|}
\hline & Specification & Type A & Type \\
\hline \multirow{7}{*}{$\begin{array}{l}\text { Laser } \\
\text { level }\end{array}$} & Horizontal accuracy & $\pm 10^{\prime \prime}$ & $\pm 10 "$ \\
\hline & Measuring distance & $1.5 \mathrm{~m} \sim 175 \mathrm{~m}$ & $\sim 100 \mathrm{~m}$ \\
\hline & Light source & Semiconductor laser & Semiconductor 1 aser \\
\hline & Beam rotating speed & $600 \mathrm{rpm}$ & $300 \mathrm{rpm}$ \\
\hline & Power supply & Dry cells & Dry cells \\
\hline & Outline dimensions & $175 \times 175 \times \quad 265 \mathrm{~mm}$ & $164 \times 164 \times 274 \mathrm{~mm}$ \\
\hline & Weight & $3.6 \mathrm{~kg}$ & $3.3 \mathrm{~kg}$ \\
\hline \multirow{5}{*}{$\begin{array}{l}\text { Attached } \\
\text { beam } \\
\text { receiver }\end{array}$} & Detection accuracy & $\pm 0.9 \mathrm{~mm}$ & High0. $8 \mathrm{~mm}$ Low $1.5 \mathrm{~mm}$ \\
\hline & Response speed & $0.5 \mathrm{sec}$ & $0.5 \mathrm{sec}$ \\
\hline & Power supply & Dry cells & Dry cells \\
\hline & Outline dimensions & $85 \times 32 \times 170 \mathrm{~mm}$ & $86 \times 36 \times 160 \mathrm{~mm}$ \\
\hline & Weight & $0.28 \mathrm{~kg}$ & $0.3 \mathrm{~kg}$ \\
\hline
\end{tabular}

Table 2. Major specifications of data memory type beam receivers for use in surveying work

\begin{tabular}{|l|c|c|c|}
\hline \multicolumn{1}{|c|}{ Specification } & Type a & Type b & Type c \\
\hline \hline Resolving power & $1 \mathrm{~mm}$ & $\pm \mathrm{mm}$ \\
\hline $\begin{array}{l}\text { Length of the beam } \\
\text { receiving section } \\
\text { Response speed }\end{array}$ & $80 \mathrm{~mm}$ & $549 \mathrm{~mm}$ & $200 \mathrm{~mm}$ \\
\hline Beam receiving angle & $2.5 \mathrm{sec}$ & $0.1 \mathrm{sec}$ & $0.1 \mathrm{sec}$ \\
\hline External interface & 60 & 40 & $360^{\circ}$ \\
\hline Power supply & RS- $232 \mathrm{C}$ & RS- 232C & RS- $232 \mathrm{C}$ \\
\hline Outline dimensions & $150 \times 50 \times 250 \mathrm{~mm}$ & $168 \times 52 \times 632 \mathrm{~mm}$ & $132 \times 156 \times 317 \mathrm{~mm}$ \\
\hline Weight & $3.0 \mathrm{~kg}$ & approx. 3.5 kg & $2.7 \mathrm{~kg}$ \\
\hline
\end{tabular}

In many cases the quality of work depends on the performance of the beam receiver used in the stage of measurement when applying an automated/robotized system to level determination work using laser levels. It is therefore necessary to set up the accuracy, response speed, displacements and range of measurement, all required for the execution of automated/robotized work. Along with these settings, selecting, modifying as well as developing a beam receiver becomes necessary.

\section{DEVELOPMENT OF CONCRETE LEVELLING ROBOT}

\subsection{Evolution of the Development}

The need for automating the work of finishing exposed concrete floor surfaces has been increasing, which has stimulated the development of mechanized robots to perform the work of finishing concrete floor surfaces in lieu of steel trowels. Dver the years, the robotization for work to 
level off the top of a fresh concrete surface has been desired by plasterers, because this determines the smoothness of a finished concrete surface; repeated concrete placing takes place simultaneously of nearly the same area; and exposed concrete surface finishing work requires the most sophisticated skill.

As the first step toward the development of an automated construction work execution technology using laser beams, approach to the robotization of concrete floor surface finishing work was made with the abovementioned situations taken into account. As a result, excellent results have been attained, and their description follows.

\subsection{Concrete Levelling Robot Overview}

(1) Specification: Figure 1 displays the exterior of the robot and Table 3 gives its major specifications.

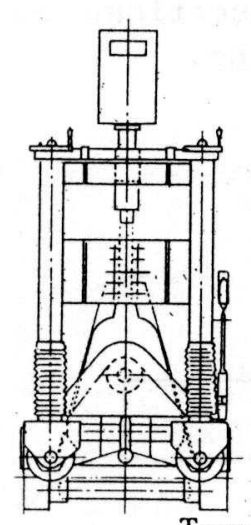

Laser beam receiver sensor

Temporary rail i

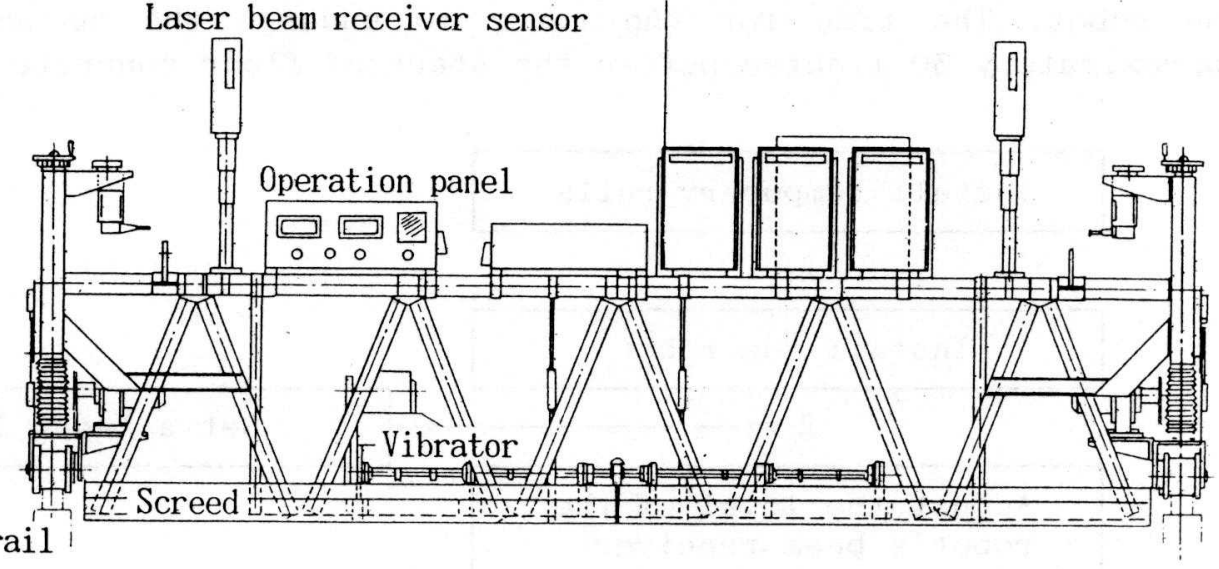

Figure 1. Exterior views of Concrete Levelling Robot

Table 3. Major specifications of Concrete Levelling Robot

\begin{tabular}{|l|l|l|}
\hline \multirow{2}{*}{ Main body } & Dimensions & $670(\mathrm{~L}) \times 3625(\mathrm{~W}) \times 1500(\mathrm{H}) \mathrm{mm}$ \\
\cline { 2 - 3 } & Weight & approx. $270 \mathrm{~kg}$ \\
\cline { 2 - 3 } & Operation method & Wireless remote-controlled operation \\
\hline \multirow{2}{*}{$\begin{array}{l}\text { Level control section } \\
\begin{array}{l}\text { Levelling } \\
\text { section }\end{array}\end{array}$} & Adjusting allowance: $\begin{array}{l}320 \mathrm{~mm} \\
\text { Sequential control }\end{array}$ \\
\cline { 2 - 3 } & Vibration method & U-shaped unbalancer tightening type \\
\cline { 2 - 3 } & Impulses & Stepless \\
\hline \multirow{3}{*}{$\begin{array}{l}\text { Travelling } \\
\text { section }\end{array}$} & Speed & Stepless $0.22 \sim 4.3 \mathrm{~m} / \mathrm{min}$. \\
\cline { 2 - 3 } & Travelling method & 4-wheels driven on rails \\
\cline { 2 - 3 } & Lateral movement & $\begin{array}{l}\text { Attached rollers provided underneath the } \\
\text { robot's main body }\end{array}$ \\
\hline
\end{tabular}

(2) Robot configuration: The robot's main body consists of a level control section, a concrete levelling section, and a travelling section. The outlines of these sections follow.

(1) Level control section: Receives the beams emitted from laser beam emitters arranged at the perimeter, and uses computers to calculate the 
necessary amount of correction. Subsequently gives a command to a servo motor about the results, moves a screed up and down and performs level control automatically with an accuracy of $\pm 1 \mathrm{~mm}$.

(2) Concrete levelling section: Gives impulses to two screeds, each located in the front and rear, by a variable vibration device capable of freely adjusting impulses and amplitude, and then commences finishing a concrete floor surface by applying adequate forces to ooze out cement paste onto the surface.

(3) Travelling section: Travels on temporarily arranged rails of square steel pipe, with speed adjustable steplessly with an inverter. Moves to a subsequent adjoing area by means of the built-in horizontal shifting roolers of the robot.

(3) Sequence of operation: Figure 2 gives the basic sequence of operating the robot. The time for the robot to undergo the necessary settings is approximately 30 minutes before the start of floor concrete placing.

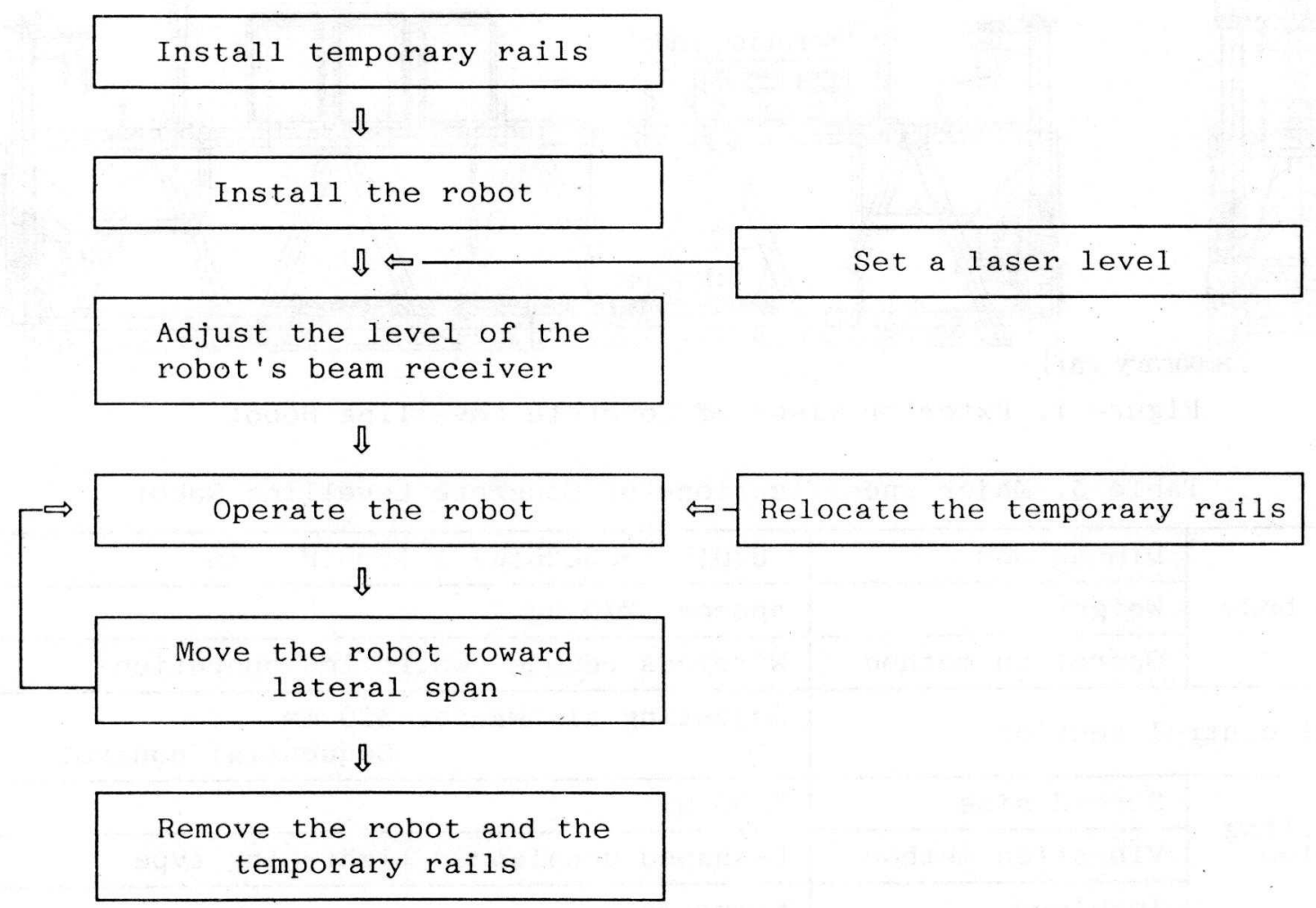

Figure 2. Basic sequence of operation for Concrete Levelling Robot

\subsection{Achievements}

The development of the robot was proceeded by targeting a certain construction site for its application. The subsequent paragraphs describe the achievements.

(1) Labor-saving: Traditionally, concrete floor surface levelling work requires three or four skilled plasterers allocated for a single nozzle on the tip of the pressure-feed piping of a concrete pump. The use of the robot did not require more than one skilled plasterer and one concrete worker (Photo 1). 


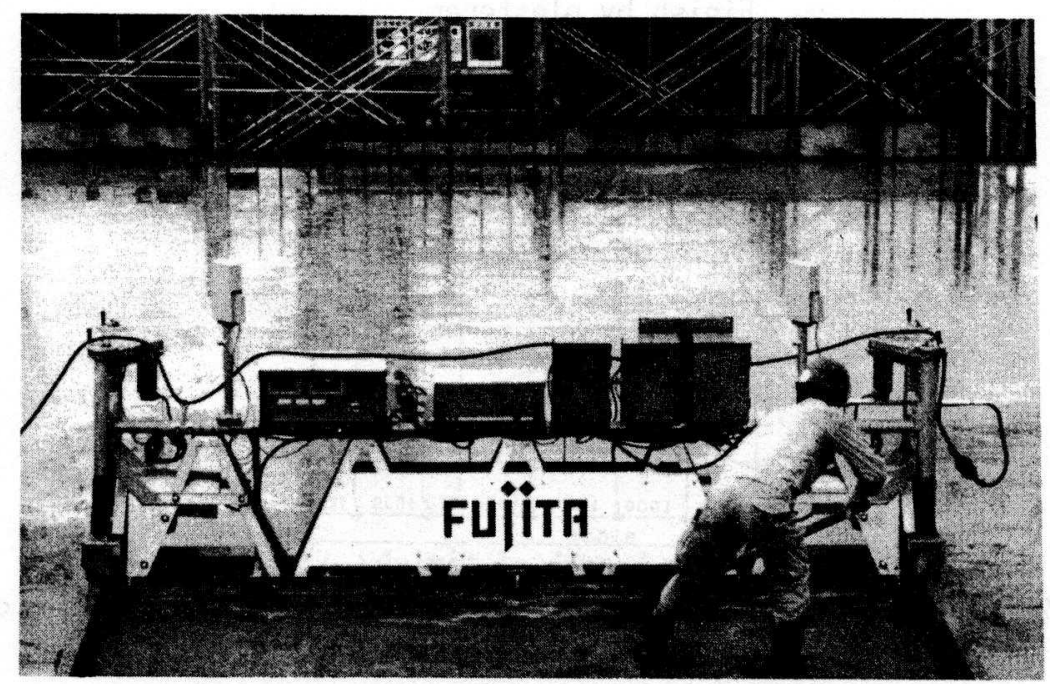

Photo 1. Concrete Levelling Robot is in the midst of levelling the concrete floor surface

(2) Ease of work execution: The robot was advancing approximately three meters behind the nozzle of the concrete pump piping. The screed was also acting as a substitute for the top level measure of concrete being cast inside the forms, which was therefore facilitating the adjustment of concrete volume to be cast. And the casting speed was equalling the leveliing speed, which therefore raised no problem of accumulating redundant concrete in front of the screed.

(3) Correlation: The following describes major problems which resulted from robotized work execution, versus their countermeasures.

(1) The robot was forced to travel along the longitudinal and vertical directions of the forms structured of one meter wide half-length precast concrete panel because the time between the cast concrete deflecting the forms and the cast concrete being levelled off would affect the levelling accuracy.

(2) Because of the effect of the deadweight of the robot on the levelling accuracy, a deviation of $1.5 \mathrm{~mm}$ was predicted under the most unfavorable condition. However, the measured deviation was no more than $1 \mathrm{~mm}$, hence no specific countermeasure was taken.

(3) Compared to traditional levelling work done by hand, the robot offers less freedom in the sequence of work execution, so as many detailed discussions as possible were made about the sequential program and also among the concrete placing hands.

(4) Levelling accuracy: Efforts were exerted in ensuring the levelling accuracy by properly controlling the travelling speed, the level control speed, and the impulses of vibrators, so that changes in the concrete properties due to different weather conditions and the quality of ready-mixed concrete manufacturing plants, could be offset. Figure 3 exemplifies the results of measurements taken of the finished conditions of adjacent concrete floor surfaces, levelled off each by the robot and plasterers. Through the execution of concrete surface finishing work by 


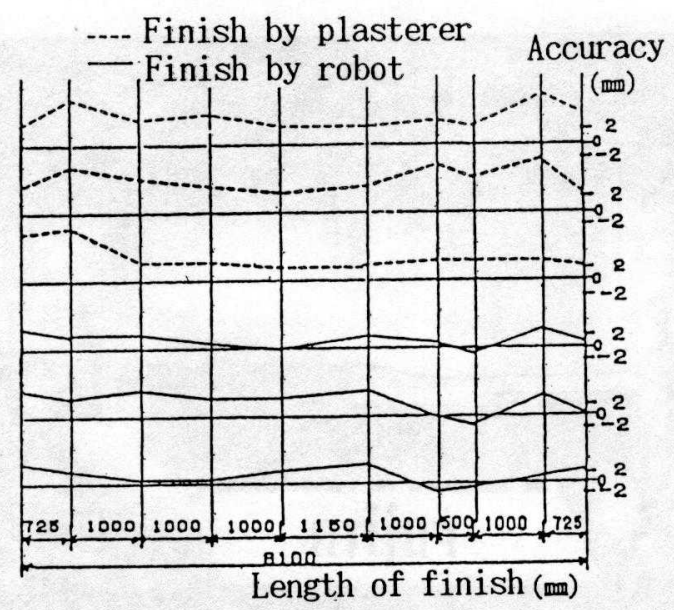

Figure 3. An example of finished concrete surface conditions

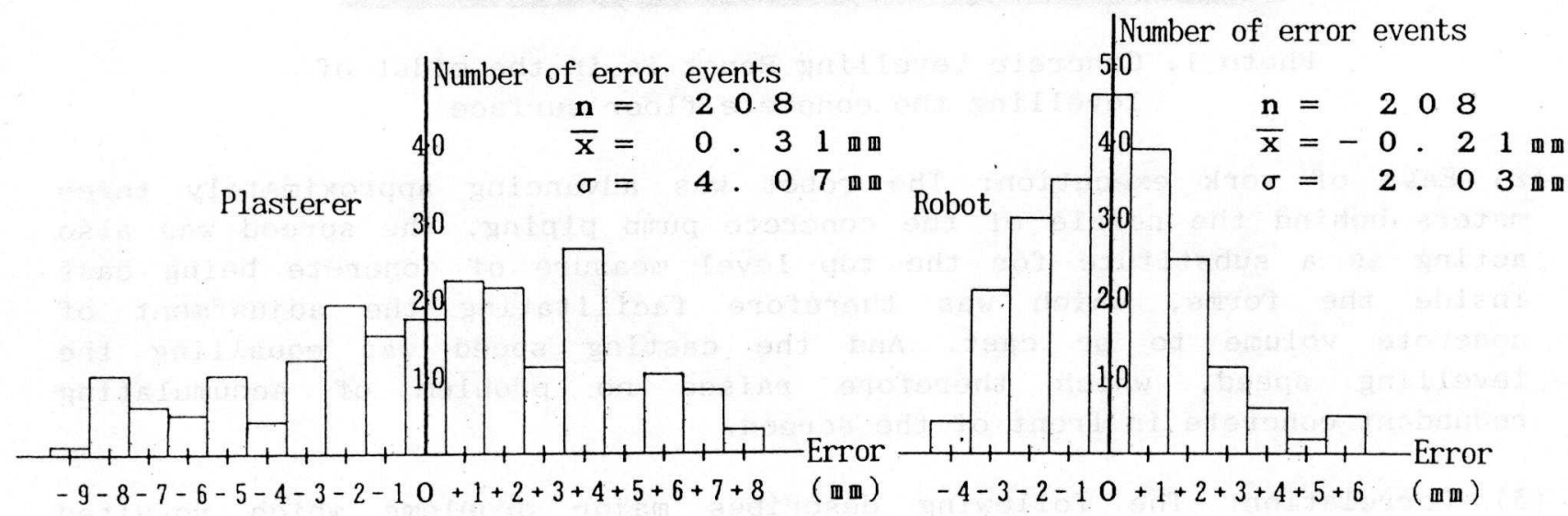

Figure 4. Distribution of finished concrete surface conditions

\subsection{Future Outlook}

The use of laser beams has enabled the confirmation of the ability of the robot to perform accurate concrete levelling work. However, in order for the robot to be used more extensively so that it can adapt to any construction site with varying working conditions, it is necessary to build up various work execution data achieved through the application of robots at a number of diverse construction sites. Based on these application results, the robot will undergo hardware and software modifications and approaches will be made from varying angles to study the method of placing floor concrete appropriate for robotized work execution.

\section{DEVELOPMENT OF AUTOMATIC LEVEL MARKER}

\subsection{Evolution of the Development}

Through the development of Concrete Levelling Robot, it was confirmed that construction machines could be controlled at an accuracy of $\pm 1 \mathrm{~mm}$ against the laser beam being emitted from a laser level. Based on these results, the development of an automatic level marker, which requires the same level determination technology in the area of mechanisms as one applied to the robot, is underway.

Traditionally, level marking work is performed by two men. For example, a line which is first marked with ink on the vertical surface one 
progress of the architectural work. This happens wherever vertical surfaces require level determination. Although level marking work is minimal, it is important in determining datum levels, hence this work requires labor-saving and mechanization.

\subsection{Outline of Automatic Level Marker}

(1) Specification: Figure 2 displays the external view of the proposed automatic level marker, and Table 4 gives its major specifications.

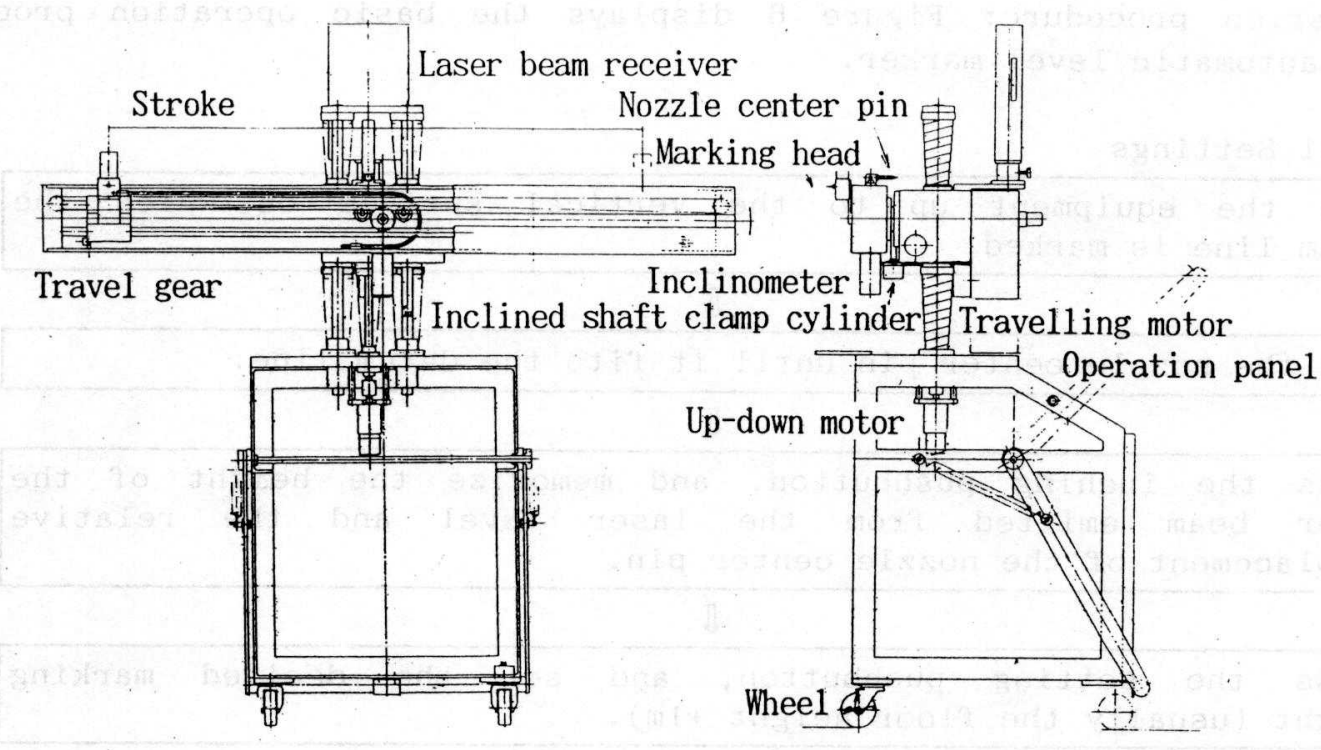

Figure 5. Exterior view of automatic level marker

Table 4. Major specifications of automatic level marker

\begin{tabular}{|l|l|}
\hline Overall dimensions & $1,294(\mathrm{~W}) \times 500(\mathrm{D}) \times 1,415 \mathrm{max} .(\mathrm{H}) \mathrm{mm}$ \\
\hline Weight & Approx. $60 \mathrm{~kg}$ \\
\hline Accuracy & $\pm 1 \mathrm{~mm}$ \\
\hline Adjustable range of height & Floor level $+900 \sim 1,100 \mathrm{~mm}$ \\
\hline Marking width & $1,000 \mathrm{~mm}$ \\
\hline Initial setting & By inching the nozzle center pin \\
\hline Ink & China ink \\
\hline Power supply & AC $100 \mathrm{~V}$ \\
\hline Means to move on the floor surface & Four wheels (by hand) \\
\hline
\end{tabular}

(2) Mechanism: The automatic level marker is comprised of driving section, a marking section and a control section. The outline of each of the sections follows.

(1) Driving section: An up-down pulse motor automatically moves up and down the beams being emitted from the laser levels located at the perimeter so that the laser receiver detects the beams to position them at the given height. Next, an inclinometer detects the degree of inclination of the marking head travel gear, which is followed by level determination by the inclination correction pulse motor. 
(2) Marking section: With a command from a controller received, a microgear pump feeds the ink inside a tank located beneath the automatic level marker to the marking head. Then the marking head drams a dotted line on the Vertical surface while driving the travel gear by means of the travelling motor.

(3) Control section: This section is comprised of a data processing section which receives signals from the laser beam receiver and the inclinometer, a shaft control section which controls all the motors, a head/pump control section, and a power supply section.

(3) Operation procedure: Figure 6 displays the basic operation procedure for the automatic level marker.

Initial Settings

Move the equipment up to the vertical surface on which the datum 1 ine is marked.

$\mathfrak{n}$

Inch the nozzle center pin until it fits the datum line.

\&

Press the inching pushbutton, and memorize the height of the laser beam emitted from the laser level and the relative displacement of the nozzle center pin.

h

Press the setting pushbutton, and set the desired marking height (usually the floor height $+1 \mathrm{~m}$ ).

Repeated Work

I

Move the equipment up to the surface requiring marking.

$\mathfrak{n}$

Press the start pushbutton.

』

Then the equipment begins up and down operations automatically to search the laser beam to determine the desired height.

b

The equipment performs inclined measurement automatically to determine the level for the travel gear.

』

The marking head works automatically to mark the required line on the subject surface.

$$
\text { \ }
$$

Then the marking head returns to its original position automatically

Figure 6. Basic operation procedure for automatic level marker

\subsection{Achievements}

The achievements of the automatic level marker follow. 
(1) Labor-saving: Traditionally, level marking work requires one skilled marking man and one helper. The automatic level marker has been proved to require only one marking man with little experience.

(2) Ease of work execution: Five to ten minutes were enough to completely teach the operator how to operate the automatic level marker. The time required for initial settings was about ten minutes after the marker was moved to the vertical surface bearing the datum level marked. The time to repeat level marking work at one place was 28 seconds. In addition as the China ink available on the market was used as the marking ink, the marking head, closed with a simple cap, was not clogged for about one month during which no cleaning of the head interior was done.

(3) Accuracy: Based on the results of an experiment on repeated marking work, the making accuracy was determined with reference to the specifications of laser levels (Table 1) and those of beam receivers (Table 2). The proposed level marker itself did not cause any accuracy errors. The product calculated according to the specifications and obtained from the experiment both presented an error of about $3 \mathrm{~mm}$ over a length of 40 meters, and about $2 \mathrm{~mm}$ against 20 meters. The width of a marking line is about $1 \mathrm{~mm}$. With the quality and accuracy of architectural work taken into account, the range of use of the proposed marker could presumably be a radius of 30 meters or less centering on the laser level.

\subsection{Future Aim}

The deveopment of level determination technology using laser beams into level marking work, which has been achieved while the development of a concrete surface levelling robot was underway, has achieved good results (Photo 2).

Continued efforts will be made to modify the proposed marker into a more utilizable unit, by improving the durability of the mechanisms, reducing the weight, improving the repeated work speed, and reducing the manufacturing cost, so that the marker will suit on-side varying environments.

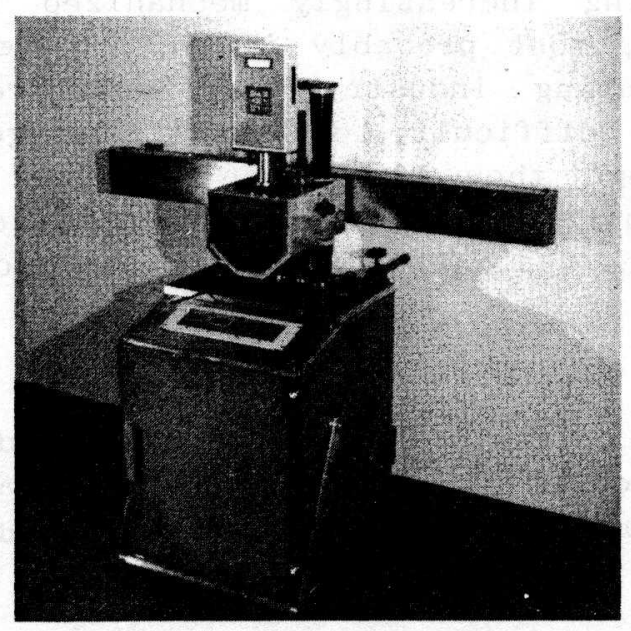

Photo 2. Overall view of automatic level marker

\section{POTENTIAL FOR LASER BEAM TO BE USED AT CONSTRUCTION SITES}

Most laser beams used at construction sites are produced by semiconductor lasers, used mainly in work requiring accurate measurement 
The types of work that can use laser beams in the determination of horizontal or vertical levels include:

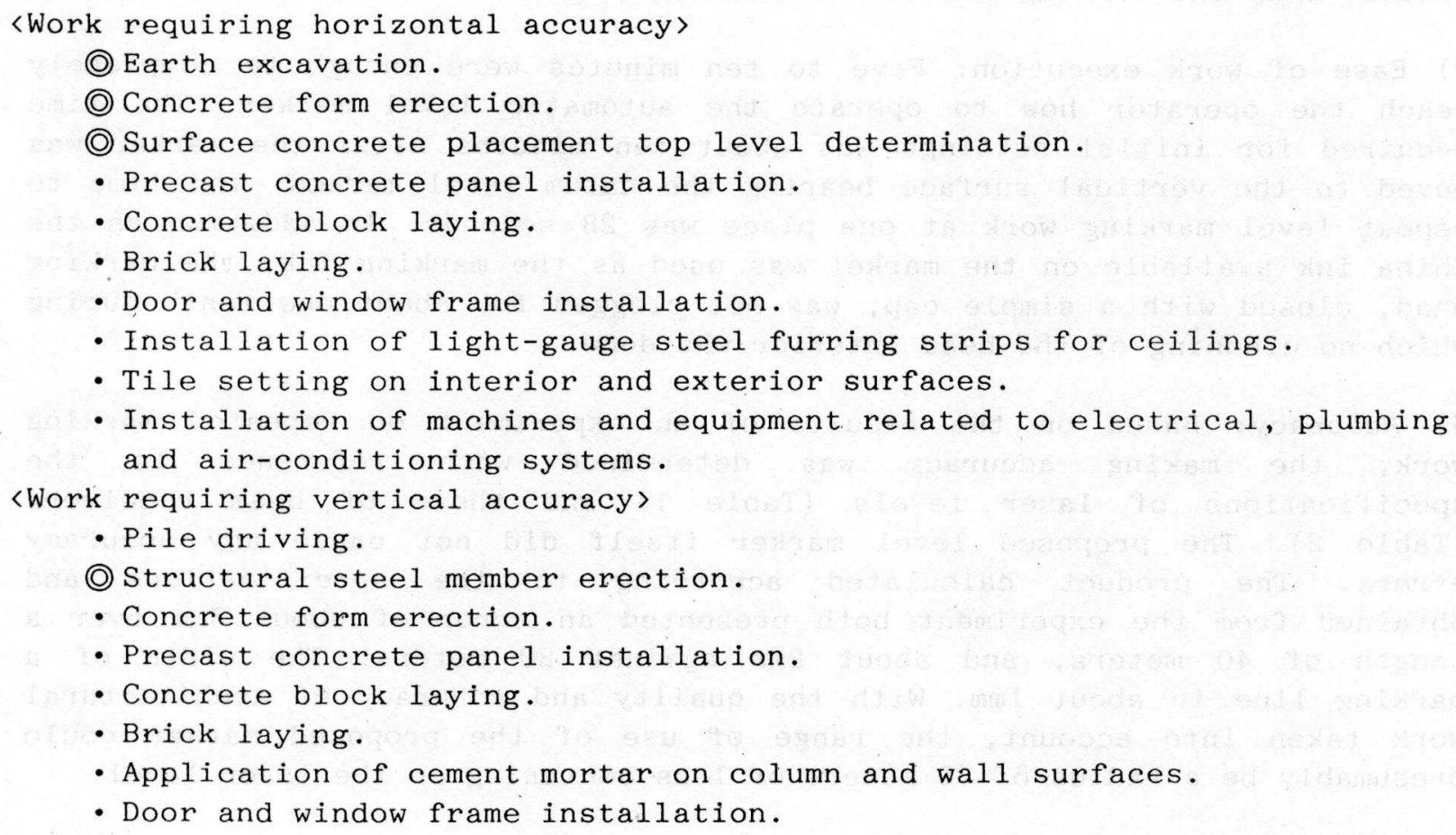

- Application of cement mortar on column and wall surfaces.

- Door and window frame installation.

Note that an item prefixed with a () mark denotes the use of laser beams.

Other types of work for which laser beams can be used include marking working positions, guiding moving objects, and work requiring cutting and fabrication.

Regarding marking working positions, a laser beam is used to mark the location of excavation being carried out in a tunnel, but has never been used in the field of building. However, attempts could be made for its introduction into this area as time has become easier for the introduction of laser pointers etc. For guiding moving objects, with work at construction sites becoming increasingly mechanized and automated, laser beams could be introduced, most probably in roles based on examples of use in the general manufacturing industry. For work requiring cutting and fabrication, it would be difficult to take advantage of laser beams at construction sites although they have been utilized considerably in the general manufacturing industry. Therefore their utilization could be mainly at building demolition sites and building parts production plants.

\section{CONCLUSIONS}

The outlines of the concrete levelling robot and the automatic level marker have been introduced as development examples of automated construction work execution technology using laser beams, and the potential for taking advantage of laser beams at construction sites has also been mentioned.

Rapid development of electronics, which dates back about fifteen years, has facilitated the use of laser beams. As the mechanization of construction work at building sites is yet to be developed, laser beams are not often utilized. Yet, the dissemination of laser beams centering on accurate measurement could advance along with increasing mechanization of work, which could further develop into automation. 